\title{
Modeling of Calcium Oxalate Kidney Stone Growth
}

\author{
Ehsan Shabani*, Mohammad J Abdekhodaie and Seyyed Abbas Mousavi
}

\begin{abstract}
Kidney stones affect about $10 \%$ of people and have become more prevalent in recent years. Also it could be a serious risk to the astronaut's health in Space. Calcium Oxalate stones $(\mathrm{CaOx})$ are the most common type of kidney stones.

In this study, the growth of the $\mathrm{CaOx}$ stones investigated by using a transport-kinetics combined model which consider both mass transfer of ions to the surface of the crystal and $\mathrm{CaOx}$ forming reaction on the surface of the crystal. Then the dependence of the crystal growth rate on different parameters such as urine supersaturation, crystal size, crystal shape and Damköhler number is investigated.

At the normal conditions (low supersaturation and small Damköhler number), the crystal growth controlled by surface reaction. But for the high supersaturation and large Damköhler number that may occur in the microgravity environment of Space, the crystal growth controlled by ions mass transfer. The crystal shape has no considerable effect. As expected, the growth rate increases with solution supersaturation increasing and lightly decreases when the crystal size increased. Also the final stone size estimated by combining this model via Robertson's kidney stone formation model.
\end{abstract}

Index Terms - kidney stone modelling, Calcium Oxalate stone, transport-kinetics combined model, astronaut's health

\section{INTRODUCTION}

Renal calculi is one of the oldest known diseases. For example, the bladder stone found in the pelvis of an Egyptian mummy which dates back to 4900 BC. Also, some samples can be found in Hippocrates' (ca. 460-370 BC) [1].

Kidney stones affect about $10 \%$ of people and have become more prevalent in recent years. Also, 20\%_40\% of people with renal stones require hospital care for pain, obstruction, or infection (For example, about 5\% of American women and 12\% of men). In addition to this severe pain, stones can lead to other problems such as surgical interventions, loss of work, and finally kidney failure in the long-term.

One of the important properties of the formed stone is stone size. Passage of a renal calculus produces renal colic which cloud be a sharp and severe pain. Stone can obstruct the uretero-pelvic junction, so the pain will localize to the flank; and when the stone moves down, pain moves downward too. Stones with diameter of less than $5 \mathrm{~mm}$ have a high chance of passage and greater than critical size stones usually require surgical or other urological intervention [2-6].

E. Shabani, M. J. Abdekhodaie and S. A. Mousavi they all are with the Sharif University of Technology, Tehran, Iran
There are different kind of kidney stones which each one has a different formation reason and different characteristics. Calcium Oxalate stones $(\mathrm{CaOx})$ are the most common type of kidney stones. Usually, this stone formation is for one of these reasons:

- High supersaturation and concentrations of crystalloids (such as hypercalciuria, hyperoxaluria, and low urine volume)

- Low concentrations of inhibitors (such as hypocitraturia)

- High concentrations of promoter substances (such as hyperuricosuria) [7]

Supersaturation (amount of the substance presence in solution at higher concentrations than its solubility) values of various substances such as Calcium and Oxalate ions in urine are used as an important indicator to determine who has a high risk of stone formation. In addition to the state of urinary supersaturation, the stone formation also depends on other parameters including the presence of inhibitors and promoters (such as citrate and nephrocalcin). However, recent researches have indicated that urinary supersaturation is an important indicator of renal calculi and could reflect the stone composition too $[5,8]$.

The kidney stone formation could be a serious risk to the astronaut's health in Space too. Unfortunately, human adaptions to the spaceflight environment, changes the urine composition which could increase the risk of renal stone formation. Efforts to prevent or at least reduce the likelihood of renal stone formation are an important aspect of protecting the astronaut's health and safety [9].

Urine is supersaturated with some salts in the kidney and crystal nucleation can occurs. In the other hand, urine also contains some chemical components and inhibitors which prevent the crystal core growth and/or aggregation or agglomeration of crystal cores. Sometimes, these inhibiting materials concentration decrease below their appropriate concentration due to different conditions such as genetics, diet, or some disease or environmental changes can cause physiological alterations. So, the stone can be formed by growth or aggregation or agglomeration of crystal cores and it may be larger than the critical size. The spaceflight environment and changing the diet and physiological conditions of crewmembers, increase the risk of kidney stone formation. $\mathrm{Ca}$ excretion increasing, low volume urine, dehydration, high sodium and protein diet and low citrate, phosphates, and magnesium in urine are the main effective factors which increase urine supersaturation and decrease inhibitors $[6,9]$. 
There are two main methods for $\mathrm{CaOx}$ stone formation modeling. Finlayson consider a system of continuous crytallizers in series and assumed a mixed suspension mixed product removal (MSMPR) conditions to estimate the stone size distribution. Then used experimental growth rates and investigated when the formed stone can block the collecting ducts and concluded particle fixation or retention of the stone must take place. Kok and Khan show that blockage is possible even without particle fixation by using more reliable data and the free-particle concept was introduced [9, 14].

Then, Kassemi focuses on the combined transport-kinetics model to predict the crystal growth rate. In previous researches, assumed that the ionic concentrations at the stone surface are equal to bulk values in the solution. So, the crystal growth controlled by the surface reaction. But in the spaceflight environment, the high supersaturation, low inhibitor concentrations and very small relative velocities may occur which might induce high Damköhler number and the transport rate will be important. To consider this, Kassemi used a transport-kinetics combined model. [9, 12-14]

In this study, the growth of the $\mathrm{CaOx}$ stones investigated by using a Kassemi transport-kinetics combined model which consider both mass transfer of ions to the surface of the crystal and $\mathrm{CaOx}$ forming reaction on the surface of the crystal. Then, the size of final stone is estimated by using the Robertson model data for total transit time through nephron.

\section{MATHEMATICAL MODEL}

In the first step, a spherical $\mathrm{CaOx}$ stone with radius $\mathrm{r}$ considered, which grows in urine at uniform bulk $\mathrm{Ca}$ and $\mathrm{Ox}$ concentrations. The crystal growth can be controlled by balance between the transport of ions from the solution bulk and the kinetics of surface reaction of ions. The growth rate of crystal can be obtained from equation 1 which can be written for $\mathrm{CaOx}$ and other simple low soluble salt crystals.

$$
\frac{d y}{d t}=K_{y} V_{m} K_{g}\left[\left(\frac{C_{C x} C_{D x} f^{2}}{x_{s}}\right)^{\frac{1}{2}}-1\right]^{2}
$$

In this equation, $\mathrm{C}_{\mathrm{Ca}}$ and $\mathrm{C}_{\mathrm{ox}}$ are the concentrations of $\mathrm{Ca}$ and Ox ions at the surface of crystal, $\mathrm{K}_{\mathrm{s}}$ is the solubility product of $\mathrm{CaOx}$ and $\mathrm{K}_{\mathrm{r}}$ is the surface reaction rate constant for precipitation of $\mathrm{CaOx}$.

So, determination of the crystallization rate, needs the surface concentrations of ions. For this purpose, mass balance written to balancing consumption of ions by the crystallization reaction at the surface of crystal with the rate of the mass transfer of ions from solution to the surface of crystal. Mass balances for each ion are shown in equation 2, 3. Because of the urine flow, the effect of convection is significantly greater than effect of diffusion in mass transfer of ions. Therefore, it could be assumed that mass transfer coefficient $\left(\mathrm{K}_{\mathrm{m}}\right)$ is equal for both $\mathrm{Ca}$ and $\mathrm{Ox}$ ions.

$$
\begin{aligned}
& K_{m}\left(C_{C a}-C_{\mathrm{ma}, C a}\right)=-K_{y} K_{g}\left[\left(\frac{C_{C x} C_{D x} f^{2}}{K_{s}}\right)^{\frac{1}{2}}-1\right]^{2} \\
& K_{m}\left(C_{O x}-C_{\mathrm{max}, O x}\right)=-K_{y} K_{g}\left[\left(\frac{C_{C x} C_{D x} f^{2}}{K_{s}}\right)^{\frac{1}{2}}-1\right]^{2}
\end{aligned}
$$

So by using these three equations, the crystal growth rate could be obtained. Also, by define a dimensionless number, the equations can rearrange to simple form. Damköhler number represents the ratio of the surface reaction rate to the mass transfer rate and defined as followed equation.

$$
D a=\frac{K_{r} K_{s} \frac{1}{2}}{K_{m}}
$$

Also, relative super saturation defined as equation 5 .

$$
R S=\left(\frac{C_{C a x_{a}} C_{D x} f^{2}}{K_{x}}\right)^{\frac{1}{2}}
$$

So, equation 2 changed to equation 6 .

$$
\left(C_{\mathrm{Ca}}-C_{\mathrm{ma}, \mathrm{Ca}}\right)=-D a \cdot K_{g^{\frac{1}{2}}}(R S-1)^{2}
$$

To evaluate the mass transfer coefficient of the ions $\left(\mathrm{K}_{\mathrm{m}}\right)$, the Sherwood number (Sh) can be estimated from an empirical equation of mass transfer in single sphere by using The Chilton-Colburn analogy. [12, 13]

$$
S h=\frac{K_{m} d}{D_{i m}}=2+0.6 \times R e^{\frac{1}{2}} S c^{\frac{1}{3}}
$$

Also, flow Reynolds number and solution Schmidt number defined as these equations:

$$
\begin{aligned}
& R e=\frac{U_{d d}}{v_{m}} \\
& S c=\frac{w_{m}}{D_{i m}}
\end{aligned}
$$

Here, $D_{\text {im }}$ is molecular diffusion coefficient, $d$ is crystal diameter, $U$ is relative crystal-fluid velocity and $v_{m}$ is kinematic viscosity of solution.

By using this set of equations for the growth of $\mathrm{CaOx}$ stone, the growth rate of stone can be calculated in each condition. The nonlinear equations can be solved numerically by Newton Raphson method.

To investigating the effect of stone shape, cylindrical shape assumed. So, the Sherwood number can be estimated from this equation:

$$
S h=\frac{K_{\mathrm{m}} \cdot d}{D_{\mathrm{im}}}=0.4 \times R e^{\frac{1}{2}} S c^{\frac{1}{3}}
$$

To estimate the final stone size, the obtained growth rate in the nephron which changed via the size of crystal, must be integrated from zero to final radius by assuming residual time.

\section{RESUltS AND DISCUSSION}

The list of used basis parameters in the analysis is shown in Table 1. [9] 
TABLE I: BASIS PARAMETERS

\begin{tabular}{|c|c|}
\hline parameter & value \\
\hline $\mathrm{V}_{\mathrm{m}}$ & $0.066(\mathrm{~L} / \mathrm{mol})$ \\
\hline $\mathrm{K}_{\mathrm{s}}$ & $3.479^{*} 10^{-9}(\mathrm{~mol} / \mathrm{L})^{2}$ \\
\hline $\mathrm{f}$ & 0.325 \\
\hline $\mathrm{k}_{\mathrm{r} 2 \mathrm{w}}$ & $120(\mathrm{~L} / \mathrm{mol})(\mathrm{L} / \mathrm{g})(1 / \mathrm{s})$ \\
\hline $\mathrm{K}_{\mathrm{r}}$ & $22(\mathrm{~L} / \mathrm{mol})(\mathrm{cm} / \mathrm{s})$ \\
\hline$\rho$ & $2200(\mathrm{~g} / \mathrm{L})$ \\
\hline $\mathrm{D}_{\mathrm{im}}$ & $10^{-4}\left(\mathrm{~cm}^{2} / \mathrm{s}\right)$ \\
\hline$v_{\mathrm{m}}$ & $8.17^{*} 10^{-3}\left(\mathrm{~cm}^{2} / \mathrm{s}\right)$ \\
\hline$\rho_{\mathrm{m}}$ & $1016(\mathrm{~g} / \mathrm{L})$ \\
\hline $\mathrm{C}_{\infty, \mathrm{Ca}}^{*}$ & $1.23 * 10^{-3}(\mathrm{~mol} / \mathrm{L})$ \\
\hline $\mathrm{C}_{\infty, \mathrm{Ox}}^{*}$ & $1.23^{*} 10^{-2}(\mathrm{~mol} / \mathrm{L})$ \\
\hline $\mathrm{U}$ & $0.5(\mathrm{~cm} / \mathrm{s}-\mathrm{fixed} \mathrm{concept})$ \\
\hline $\mathrm{RS}$ & 20 \\
\hline $\mathrm{R}$ & $2.5^{*} 10^{-4}(\mathrm{~cm})$ \\
\hline $\mathrm{Da}$ & $0.0015($ for $\mathrm{Ur}=0.5 \mathrm{~cm} / \mathrm{s})$ \\
\hline
\end{tabular}

The growth rate of spherical crystal with the Damköhler number is shown in Fig. 1 for different supersaturations of urinary. In the small $\mathrm{Da}$ (where crystallization is controlled by the surface reaction) the growth rate varies linearly with Da for different values of the relative solution supersaturation. But, in the large $\mathrm{Da}$ (where crystallization is controlled by the transport process) the growth rate becomes independent of the Da and reaction rate. Also, at larger supersaturations, magnitude of the growth rate is higher.

The cylindrical stone assuming leads to similar results which is presented in Fig. 2. So, it seems the shape of crystals, does not have a big effect on the crystal growth rate. So, for step forward, spherical shape assumed for crystals.

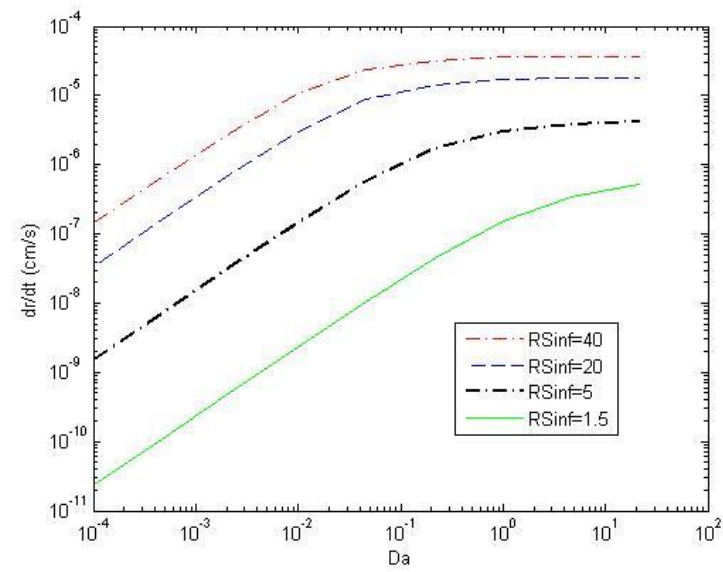

Fig. 1: Growth rate (spherical crystal) in different supersaturations.

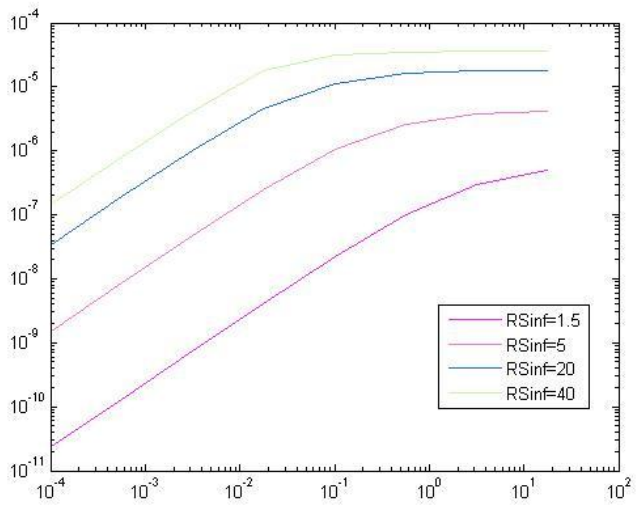

Fig.2: Growth rate (cylindrical crystal) in different supersaturations.

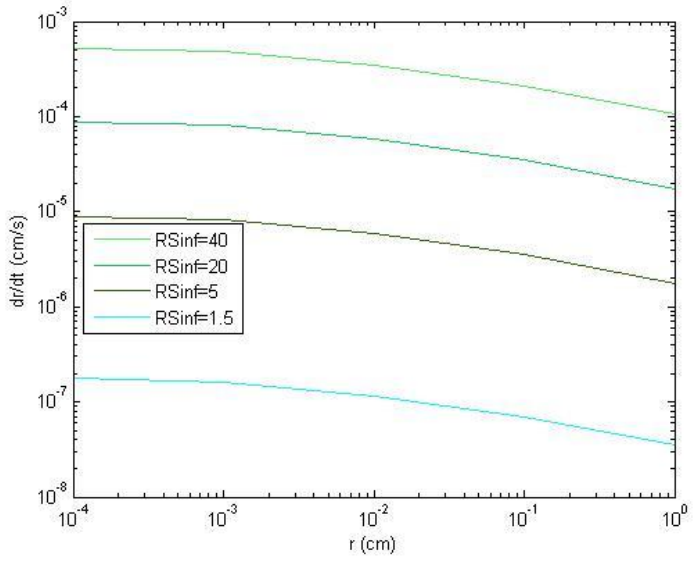

Fig. 3: Growth rate changes via crystal size in different supersaturations.

In the next step, the growth rate changes investigated via the crystal size which is presented in Fig. 3 in different supersaturations. As it expected, the growth rate decrease when the crystal size increased.

Robertson model presented the total transit time through nephron between 137 to $241 \mathrm{~s}$ (average $=189 \mathrm{~s}$ ) [14]. So, the final stone size can be obtained by integration of growth rate achieved from Fig. 3. By using this method, the final stone size limits presented in Table 2. It shown that the higher supersaturation, cause the larger stone size which may larger than the critical size.

TABLE II: FINAL STONE SIZE ESTIMATION.

\begin{tabular}{|c|c|c|c|}
\hline $\mathrm{RS}_{\infty}$ & Minimum size $(\mathrm{cm})$ & Maximum size $(\mathrm{cm})$ & Average size $(\mathrm{cm})$ \\
\hline 1.5 & $1.41 * 10^{-4}$ & $1.94 * 10^{-4}$ & $1.73 * 10^{-4}$ \\
\hline 5 & $8.63 * 10^{-3}$ & $1.16^{*} 10^{-2}$ & $9.68 * 10^{-3}$ \\
\hline 20 & $7.24 * 10^{-2}$ & $9.72^{-2} 10^{-2}$ & $8.93 * 10^{-2}$ \\
\hline 40 & 0.567 & 0.631 & 0.612 \\
\hline
\end{tabular}

\section{CONCLUSION}

In this study, the growth of the $\mathrm{CaOx}$ stones investigated by using a transport-kinetics combined model which consider both mass transfer of ions to the surface of the crystal and $\mathrm{CaOx}$ forming reaction on the surface of the crystal. The crystal growth rate dependence on urine supersaturation, crystal size, crystal shape and Damköhler number is studied.

The crystal shape has no considerable effect, the growth rate increases with solution supersaturation increasing and decreases with the crystal size increasing. Also the final stone size estimated by using Robertson's kidney stone formation model for the total transit time through nephron. It was Confirmed that the higher supersaturation, cause the larger stone size which may larger than the critical size.

\section{REFERENCES}

[1] A. Caballero, J.F. Molinari, Finite element simulations of kidney stones fragmentation by direct impact: Tool geometry and multiple impacts, International Journal of Engineering Science 48,2010, 253-264 https://doi.org/10.1016/j.ijengsci.2009.11.002

[2] Michael G. Selby, Terri J. Vrtiska, Amy E. Krambeck, Cynthia H. McCollough, Hisham E. Elsherbiny, Eric J. Bergstralh, John C. Lieske, and Andrew D. Rule, Quantification of Asymptomatic Kidney Stone 
Burden by Computed Tomography for Predicting Future Symptomatic Stone Events, UROLOGY 85 (1), 2015, 45-50 https://doi.org/10.1016/j.urology.2014.08.031

[3] Fredric L. Coe, Andrew Evan, Elaine Worceste, Kidney stone disease, The Journal of Clinical Investigation, 115 (10), 2005, 2598-2608 https://doi.org/10.1172/JCI26662

[4] Ouyang Jianming, Yao Xiuqiong, Su Zexuan, Cui Fuzhai, Simulation of calcium oxalate stone in vitro, Simulation of calcium oxalate stone in vitro, 46 (3), 2003

[5] Robert A. Pietrzyk, Alan H. Feiveson, Peggy A. Whitson, Mathematical Model to Estimate Risk of Calcium-Containing Renal Stones, Miner Electrolyte Metabolism, 25, 1999, 199-203 https://doi.org/10.1159/000057445

[6] Dan L. Longo, Anthony S. Fauci, Dennis L. Kasper, Stephen L. Hauser, J. Larry Jameson, Joseph Loscalzo, Harrison's Principles of Internal Medicine, $18^{\text {th }}$ ed., part 13, McGraw-Hill Professional, 2011

[7] Raven Goel, Alan G. Wasserstein, Kidney Stones: Diagnostic and Treatment Strategies, Consultant, 52 (2), 2012

[8] Parks J.H., Coward M., Coe F.L., Correspondence between stone composition and urine supersaturation in nephrolithiasis, Kidney Int, 51, 1997, 894-900 https://doi.org/10.1038/ki.1997.126

[9] M. Kassemi, R. Brock, N. Nemeth, A combined transport-kinetics model for the growth of renal calculi, Journal of Crystal Growth, 332, 2011, 48-57 https://doi.org/10.1016/j.jcrysgro.2011.07.009

[10] John Edward Hall, Arthur C. Guyton, Guyton and Hall Textbook of Medical Physiology, Saunders/Elsevier, 2011

[11] A. Borissova, G. E. Goltz, J. P. Kavanagh, T. A. Wilkins, Reverse engineering the kidney: modelling calcium oxalate monohydrate crystallization in the nephron, Med BiolEngComput, 48, 2010, 649-659 https://doi.org/10.1007/s11517-010-0617-y

[12] R.B. Bird, W.E. Stewart, E.N. Lightfoot, Transport Phenomena, John Wiley \& Sons, New York, 2002

[13] J.P. Holman, Heat Transfer, $6^{\text {th }}$ ed., Mc Graw-Hill, New York, 1986

[14] W.G. Robertson, Kidney Models of Calcium Oxalate Stone Formation, Nephron Physiology, 98, 2004, 21-30 https://doi.org/10.1159/000080260

\section{NOMENCLATURE}

C concentration at the surface $(\mathrm{mol} / \mathrm{L})$

$\mathrm{C}_{\infty} \quad$ bulk liquid concentration $(\mathrm{mol} / \mathrm{L})$

$\mathrm{Ca}$ calcium

$\mathrm{CaOx}$ calcium oxalate

d crystal diameter, $2 \mathrm{r}(\mathrm{cm})$

Da Damkohler number

$\mathrm{D}_{\mathrm{im}} \quad$ molecular diffusion coefficient $\left(\mathrm{cm}^{2} / \mathrm{s}\right)$

f activity coefficient

$\mathrm{K}_{\mathrm{m}} \quad$ convective mass transfer coefficient $(\mathrm{cm} / \mathrm{s})$

$\mathrm{k}_{\mathrm{r} 2 \mathrm{w}} \quad$ seeded reaction rate constant $(\mathrm{L} / \mathrm{mol})(\mathrm{L} / \mathrm{g})(1 / \mathrm{s})$

$\mathrm{K}_{\mathrm{r}} \quad$ surface reaction rate constant, $(1 / 3) \rho \mathrm{rk}_{\mathrm{r} 2 \mathrm{w}}(\mathrm{cm} / \mathrm{s})(\mathrm{L} / \mathrm{mol})$

$\mathrm{K}_{\mathrm{s}} \quad$ equilibrium solubility product $(\mathrm{mol} / \mathrm{L})^{2}$

$\mathrm{M}_{\mathrm{w}} \quad$ molecular weight $(\mathrm{g} / \mathrm{mol})$

Ox oxalate

$\mathrm{r}$ crystal radius $(\mathrm{cm})$

Re flow Reynolds number $\left(\mathrm{Ud} / v_{\mathrm{m}}\right)$

RS relative super saturation $\left[\mathrm{CcaCoxf} / \mathrm{K}_{\mathrm{s}}^{2}\right]^{1 / 2}$

$\mathrm{RS}_{\infty}$ bulk relative super saturation

Sh Sherwood number $\left(\mathrm{K}_{\mathrm{m}} \mathrm{d} / \mathrm{D}_{\mathrm{im}}\right)$

Sc solution Schmidt number

U relative crystal - fluid velocity $(\mathrm{cm} / \mathrm{s})$

$\mathrm{t}$ time (s)

$\mathrm{V}_{\mathrm{M}}$ molar volume $(\mathrm{Mw} / \mathrm{r})$

$\rho \quad$ crystal density $(\mathrm{g} / \mathrm{L})$

$\rho_{\mathrm{m}} \quad$ density of the solution $(\mathrm{g} / \mathrm{L})$

$v_{\mathrm{m}} \quad$ kinematic viscosity $\left(\mathrm{cm}^{2} / \mathrm{s}\right)$ 